IOS Press

\title{
Thesis
}

\section{A stress-awareness approach to safer decision making in the trading process integrating biometric sensor technology}

\author{
J. Martínez Fernández \\ University Carlos III Madrid, Spain \\ Currently at: HTWG Konstanz, Germany
}

Keywords: Self-awareness, stress, biometric sensors

On June 15, 2012, Javier J. Martínez Fernández defended his PhD dissertation at University Carlos III Madrid, Spain, entitled; "A stress-awareness approach to safer decision making in the trading process integrating biometric sensor technology". A great part of the research was funded by Spanish Ministry of Education under the project ARTEMISA (TIN2009-14378C02-02). Javier defended his dissertation in a publicly open ceremony held in the University Carlos III Madrid, and was able to comment on every question raised by the assessing committee. The thesis was supervised by prof. Dr. R. Seepold and co-supervised by Dr. N. Martinez Madrid. An important part of this research was carried out during a year stay at University of Ulster, UK, supervised by Dr. J.C. Augusto.

\section{Thesis summary}

The role of the global economy is fundamentally important to our daily lives. The stock markets reflect the state of the economy on a daily basis. Traders are the workers within the stock markets who deal with numbers, statistics, company analysis, news and many other factors that influence the economy in real time. However, whilst making significant decisions within their workplace, traders must also deal with their own emotions. In fact, traders have one of the most stressful professional occupations. Multiple disciplines, from programs with artificial intelligence to complex mathematical functions, are used to help traders in their effort to maximize profits. However, an essential problem yet not considered in this rapidly evolving environment is that traders are not adequately supported to manage how stress influences their decisions. Currently, traders are not fully aware of how their stress levels jeopardize safe decision making. This work, taking into consideration the known influences of stress on biometric changes, proposes a system, based in biometric principles for trading context [1], designed to cover this information gap and to minimize the likelihood of poor decision making. The system has been designed bearing in mind technical, physiological and usability aspects to show the information in a suitable way. Biometric sensors are used to collect data associated with stress and a software platform based on a new architecture (Self-Aware architecture) has been developed to collect, analyse and display this information. This architecture [2] is derived from a general model where the trading context will be a specific case used to validate the system. This resulting system is capable 


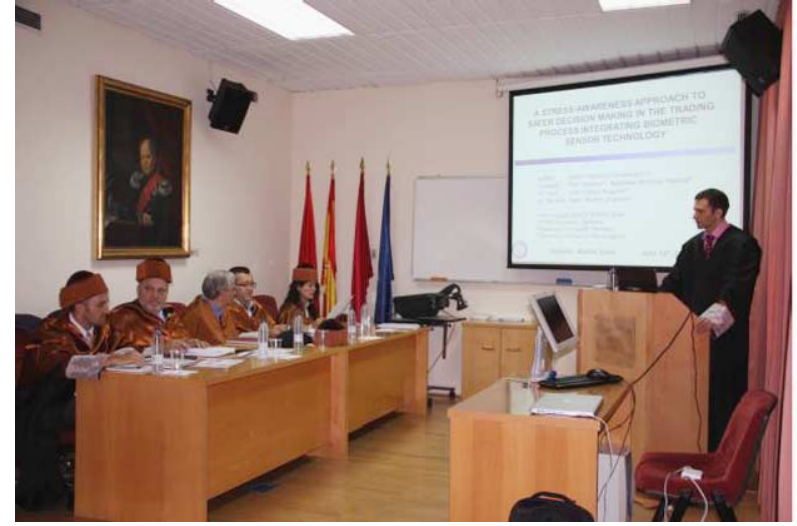

of efficiently providing self-aware information for individual traders and self-aware collective information for teams of traders in trading companies. The system was tested in a real environment and the results provide evidence that self-aware traders could positively improve their daily final balance and diminish risky decision making. These results also suggest that the analysis techniques used to forecast market trends are likewise suitable to study traders' stress level evolution [3]. This work opens up a new way for other researchers to take up the challenge of investigating the issues raised as combinations of different disciplines such as trading (economy), stress (medical) and sensors (technological).

\section{References}

[1] J. Martínez, J.C. Augusto, R. Seepold, and N. Martínez, A sensor technology survey for a stress aware trading process, IEEE

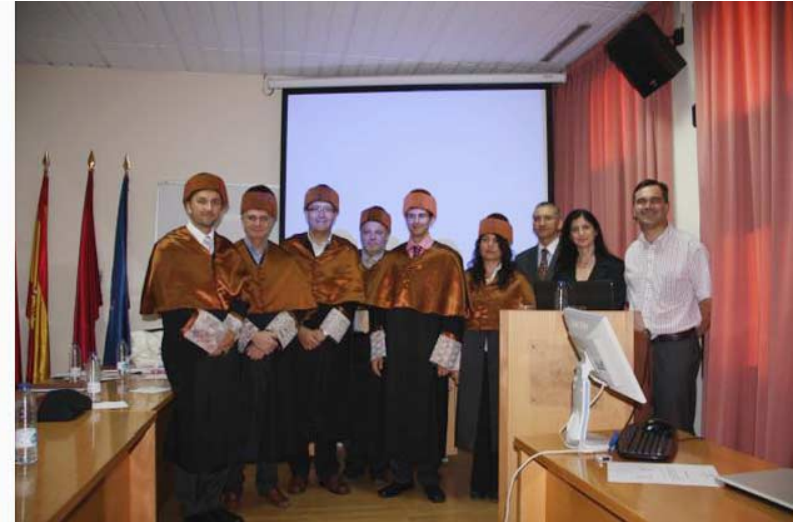

Trans. On Systems, Man and Cybernetics - Part C: Applications and reviews, in print, available for early access, DOI: http://dx.doi.org/10.1109/TSMCC.2011.2179028.

[2] J. Martínez Fernández, J.C. Augusto, R. Seepold, and N. Martínez Madrid, AmI support for the trading process: Selfaware trader model, in: Ambient Intelligence - Software and Applications, P. Novais et al., eds, Book series: Advances in intelligent and soft computing, Vol. 92, Springer, Berlin/Heidelberg, 2011, pp. 1-8. ISBN: 978-3-642-19936-3.

[3] J. Martínez, G. Trombino, R. Seepold, and N. Martínez, Realtime sensor monitoring correlation to technical analysis, in: Proc. 9th IEEE Workshop on Intelligent Solutions in Embedded Systems (WISES2011), Germany, July, IEEE Catalog Number CFP10848-PRT, 2011, pp. 7-12. Print ISBN: 978-3-00-033401-6, URL: http://ieeexplore.ieee.org/stamp/stamp.jsp?tp=\&arnumber $=$ $6086009 \&$ isnumber $=6086005$. 